\title{
OTRO HORÓSCOPO DE CRISTO EN LA PLATERÍA COMPLUTENSE DEL SIGLO XVI
}

\author{
ANOTHER HOROSCOPE OF CHRIST IN THE \\ COMPLUTENSE SILVERWORK OF THE $16^{\text {th }}$ CENTURY
}

\author{
Carmen Heredia Moreno \\ Universidad de Alcalá. España \\ carmen.heredia@uah.es
}

\begin{abstract}
El artículo estudia la cruz procesional de Puebla de Valles (Guadalajara) en el ámbito de la platería complutense de la segunda mitad del siglo XVI y en relación con los plateros Gaspar de Guzmán y Marcos Hernández. También analiza su programa iconográfico en el contexto de la Iglesia de Toledo y señala su carácter excepcional en el panorama de la platería española contemporánea.

Palabras clave: platería; siglo XVI; Gaspar de Guzmán; Marcos Hernández; horóscopo.
\end{abstract}

This paper studies the processional cross of Puebla de Valles (Guadalajara) in the scope of the Complutense silverwork in the second half of the $16^{\text {th }}$ century and in relation to silversmiths Gaspar de Guzmán and Marcos Hernández. It also analyzes its iconographic program in the context of the Church of Toledo and shows its exceptional character in the panorama of contemporary Spanish silverwork.

Keywords: silverwork; $16^{\text {th }}$ century; Gaspar de Guzmán; Marcos Hernández; horoscope.

En la exposición "Atempora" celebrada en el Museo Diocesano de Sigüenza durante los meses de junio a noviembre de 2016, he tenido ocasión de analizar con detalle la cruz procesional de la parroquia de San Miguel de Puebla de Valles (Guadalajara), una pieza de la segunda mitad del siglo XVI, de muy buena factura, que, pese a su calidad, había pasado prácticamente desapercibida para expertos e historiadores de arte hasta estos momentos. La situación geográfica de Puebla en la sierra norte de la provincia, su reducido tamaño y, sobre todo, la pérdida casi completa del archivo parroquial, deben haber sido factores determinantes para que los investigadores raras veces se hayan ocupado del patrimonio 
artístico de esta villa. Por ello, aparte de alguna breve alusión a su parroquia, la bibliografía es prácticamente inexistente.

Madoz solo indica de forma escueta que Puebla de Valles pertenece al partido judicial de Tamajón y que cuenta con una iglesia dedicada a San Miguel ${ }^{1}$. Catalina García no la menciona en el Catálogo Monumental de Guadalajara ${ }^{2}$. Tampoco se recoge en el conocido trabajo de Herrera Casado sobre cruces procesionales ${ }^{3}$. El Inventario artístico de la provincia incluye la localidad en el partido judicial de Cogolludo y describe brevemente la parroquia mencionando en su capilla mayor una "cruz, también en plata, del siglo XVI"4. Gutiérrez García Brazales indica el nombre de algún artífice que trabajó para la localidad, como el bordador toledano Pedro Calderón, a quien en 1621 se le encargó un terno blanco de menos de 4.000 reales $^{5}$. Por último, en una reciente monografía se abordan diversos aspectos sobre las costumbres, tradiciones o paisajes de Puebla y se repiten los datos sobre la parroquia dados a conocer en el Inventario, pero tampoco se intenta profundizar en el estudio de su patrimonio artístico ${ }^{6}$.

Esta falta de atención por parte de los estudiosos y el uso frecuente de la cruz en las procesiones religiosas del municipio, con los consiguientes golpes y desperfectos accidentales, han contribuido a su olvido y a su deterioro a lo largo del tiempo, hasta que en el año 2010, tras la rehabilitación de la iglesia, se procedió a restaurarla para devolverle su primitivo esplendor ${ }^{7}$. Así la he podido contemplar en la catedral de Sigüenza con motivo de la mencionada exposición, donde

${ }^{1}$ MADOZ, Pascual: Diccionario geográfico-estadístico-histórico de España y sus posesiones de ultramar. Vol. XIII. Madrid, 1845-1850, p. 253.

2 CATAliNA GARCÍA, Juan: Catálogo Monumental de Guadalajara. Edic. CDRom, 2003.

${ }^{3}$ HERRERA CASADO, Antonio: "Orfebrería antigua de Guadalajara (algunas notas para su estudio)", Wad-al Hayara, 4, 1977, pp. 7-97.

${ }^{4}$ AZCÁRATE RISTORI, José M ${ }^{\text {a }}$ (dir.): Inventario artístico de Guadalajara y su provincia. T. II. Madrid, 1983, pp. 95-97.

${ }^{5}$ GUTIÉRREZ GARCÍA-BRAZALES, Manuel: Artistas y artifices barrocos en el Arzobispado de Toledo. Toledo, 1982, p. 262.

${ }^{6}$ SANZ IRUELA, Manuel y MARTÍN MACÍAS, Francisco: Puebla de Valles. Usos, costumbres, cuentos y leyendas. Guadalajara, 2006, pp. 49-52.

7 Tiene unas dimensiones aproximadas de $102 \times 78,5 \mathrm{~cm}$ y fue restaurada en Toledo en el año 2010 en el Centro de Restauración y Conservación de la Comunidad de Castilla-La Mancha por doña María Dolores Ortín Arranz. Según su informe técnico, la obra se encontraba en muy mal estado, con deformaciones producidas por golpes y cortes, soldaduras de estaño añadidas, pérdida parcial de algunos perillones, grietas en el alma de madera y material deteriorado por abrasiones, roturas y micro fisuras. La limpieza general y la eliminación de las soldaduras, así como la reposición de las piezas que faltaban, ha devuelto a la cruz su aspecto original. Mi agradecimiento a don Miguel Ángel Ortega Canales, director del Museo Diocesano de Sigüenza, y a don José Domingo Delgado Bedmar, que me facilitaron el acceso al informe técnico sobre la restauración. Agradezco también al párroco de 
se ha exhibido y se ha dado a conocer por primera vez fuera de sus límites locales (Figura 1).

La cruz es de plata parcialmente dorada sobre alma de madera, fundida, cincelada y grabada. Lleva marcas de castillo/ALC/ALA, MAR/COS y G/CVZMAN que acreditan su procedencia de Alcalá de Henares, aunque también plantean algunos interrogantes que trataremos de resolver (Figura 2). El árbol es una cruz latina de brazos planos con el cuadrón y extremos circulares, y borde mixtilíneo perfilado por cintas de cartela. Al contorno se ajustan perillones en la zona del cuadrón; otros perillones sobre cabezas veladas y ramilletes, en los medallones circulares, y pequeñas conchas, sobre los tramos rectos. La superficie de estos últimos va cubierta de óvalos, ramilletes y cabezas de querubines. En los medallones del anverso del brazo vertical se reproducen relieves del pelícano con tres crías y la Magdalena penitente a los pies de Cristo, mientras que en los del brazo horizontal se representan María y San Juan, todos arrodillados y en actitud orante. El conjunto está presidido por una monumental figura del Crucificado muerto, de bulto redondo y de potente anatomía, con la cabeza coronada de espinas e inclinada hacia su derecha y los pies atravesados por un solo clavo. Se cubre con un breve paño de pureza de pliegues finos y paralelos.

Sirve de fondo a la cabeza de Cristo un relieve de la esfera armilar que reproduce con pequeñas variantes el de la cruz de Santorcaz (Madrid), que el platero complutense Gaspar de Guzmán terminaba de cobrar en el año 1577, según consta en el correspondiente libro de fábrica del archivo de la parroquia ${ }^{9}$. Ambos relieves son excepcionales en el panorama artístico de nuestro siglo XVI y los únicos que se conocen con esta temática en la platería española del quinientos ${ }^{10}$,

Puebla de Valles, don Fidel Blasco, su información sobre la localización de la cruz y sobre el archivo parroquial.

${ }^{8}$ Exposición "Atempora", Catedral de Sigüenza, septiembre-noviembre 2016. DELGADO BEDMAR, Domingo: "Cruz de Puebla de Valles", en CABALLERO KLINK, Alfonso (com.): Atempora. Toledo, 2016, pp. 408-409.

9 HEREDIA MORENO, Carmen y LÓPEZ-YARTO LIZALDE, Amelia: "La cruz de Santorcaz (Madrid), una obra desconocida del platero complutense Gaspar de Guzmán", Archivo Español de Arte, 283, 1998, p. 261. Un documento inédito procedente del Archivo General de Indias (A.G.I.), Indiferente, 425, leg. 23, f. 496r, menciona a un Gaspar de Guzmán que obtuvo licencia el 27 de agosto de 1560 para pasar a Indias 200 ducados en joyas de oro y plata labrada pagando los derechos correspondientes. Si la noticia se refiriese a nuestro platero, tendríamos que deducir que Gaspar era ya un maestro de prestigio en estos momentos, capaz de exportar sus trabajos hasta el Nuevo Mundo a través del comercio transatlántico en la Carrera de Indias.

${ }^{10}$ Sí se conocen algunos otros ejemplos en relieves y pinturas de la Edad Media y del siglo XVI, estudiados por ESTEBAN LORENTE, Juan Francisco: "Horóscopos artísticos de Cristo en el Románico y el Renacimiento", Boletín del Museo e Instituto Camón Aznar, XCIX, 2007, pp. 103-166. 
ambos proceden del mismo centro platero y ambos se relacionan con el mismo artífice, aunque con ciertos matices, como luego veremos.

En los medallones extremos del reverso se distribuyen las imágenes de los evangelistas, sedentes sobre nubes y acompañados de sus respectivos símbolos. San Juan y San Mateo, en el brazo vertical, y San Lucas y San Marcos, en el horizontal. Todos presentan potentes anatomías romanistas y se envuelven en amplios ropajes. Preside el reverso la figura de San Miguel, titular de la parroquia, en actitud victoriosa sobre el demonio caído a sus pies (Figura 3). Esta imagen es casi de bulto redondo, excepto sus alas y los paños volados del manto que lo enmarcan a izquierda y derecha. Por lo demás, su cuerpo solo se cubre con un escueto paño de pureza, lleva la cabeza descubierta y blande un escudo, en lugar de la completa indumentaria militar y de los demás atavíos guerreros con que suele representarse -coraza, faldellín, casco, botas y espada-. Todo ello resulta inusual en la iconografía del arcánge ${ }^{11}$. Además, su porte general y su escaso atuendo reproducen de manera casi idéntica los de la figura del Resucitado de la cruz de la parroquia de Valdeavero (Madrid), que el platero toledano-complutense Marcos Hernández había concluido antes del año 1575 y que se repite también en las cruces de la catedral de Jaén y de la parroquial de Orgaz (Toledo), obras del mismo artífice (Figura 4) $)^{12}$.

La manzana de la cruz de Puebla reproduce un templete circular de cuerpo único articulado por términos exentos, mitad figuras femeninas y mitad estípites, con el torso cubierto por mantos terciados, que apoyan en volutas sobre cabezas de animales y que sujetan trozos de entablamento culminados en pirámides herrerianas con bolas (Figura 5). En el cuerpo se abren seis hornacinas de medio punto con veneras entre cartelas y óvalos que culminan en un friso corrido con decoración de ramilletes vegetales. En las hornacinas se insertan placas fundidas con las figuras erguidas de cuerpo entero de los apóstoles San Pedro, San Juan, Santiago el Mayor, San Andrés, San Felipe y San Pablo, acompañados de sus respectivos símbolos iconográficos. Todas ellas presentan actitudes variadas, potentes anatomías de carácter romanista y largas túnicas con amplios mantos. Corona el conjunto un tambor cilíndrico con decoración de cartelas, sujeto por pequeños atlantes y con jarrones fundidos en el remate. La manzana apoya en un corto fuste cilíndrico y bulboso coronado por un grueso toro y se decora con cintas de cartela entrelazadas, cabezas femeninas veladas y atlantes de torso desnudo

${ }_{11}$ REAU, Louis: Iconografía del arte cristiano. T. 1, vol. 1. Barcelona, 1996, pp. 65-66, considera a San Miguel el jefe de la milicia celeste que lucha con el dragón blandiendo la espada o la lanza, según idearon los clérigos de la Edad Media.

12 HEREDIA MORENO, M. Carmen y LÓPEZ-YARTO ELIZALDE, Amelia: "Una aproximación a la obra del platero Marcos Hernández y a sus fuentes iconográficas y decorativas", Cuadernos de Arte e Iconografia, 16, 1999, p. 337, fig. 19 y pp. 323-324. 
y cabezas de animales. Tanto los soportes como los remates herrerianos y los ramilletes parecen obra de fundición.

Como puede apreciarse, la traza del nudo repite en líneas generales la de la macolla de la cruz parroquial de Bujalaro (Guadalajara) que Gaspar de Guzmán estaba realizando en torno a 1570, en la línea de la de Pioz (Guadalajara), obra de Antonio Faraz en posible colaboración con el propio Guzmán ${ }^{13}$. En cambio, el perfil recortado del árbol se aproxima al de la cruces de Valdeavero, Orgaz y Jaén, obra de Marcos Hernández de los años 70, y al de la de Santorcaz que Guzmán terminaba de cobrar en el 1577.

La decoración de cartelas y términos se sitúa también en la línea de estas últimas obras, si bien forma parte del lenguaje habitual del repertorio manierista y conecta con los temas creados por Antonio Fantucci a partir de los estucos de Fontainebleau entre 1537-1540, las series de términos de Agostino Veneciano de 1536 o las de Cornelis Floris hacia 1554, grabadas después por Cornelis de Bos y repetidos por Vredeman de Vries, que tuvieron rápida difusión y aceptación por Europa $^{14}$.

Por lo que concierne a la iconografía, los medallones circulares del árbol reproducen el tema del pelícano con tres polluelos y las imágenes de la Virgen, San Juan, la Magdalena y los cuatro evangelistas, igual que en Bujalaro, aunque en Puebla las del reverso son de cuerpo entero en lugar de medias figuras. También se repite la iconografía de Bujalaro en las hornacinas del nudo, si bien el diseño de los apóstoles se aproxima a los correspondientes de la manzana de la cruz de Valdeavero, utilizándose en algún caso el mismo modelo de Marcos Hernández. Así sucede, por ejemplo, con la imagen de San Felipe.

Respecto a San Miguel que es de mayor tamaño y relieve que los anteriores, tanto su advocación como su ubicación en lugar preferente del reverso del árbol se deben al hecho de ser el santo titular de la parroquia. Pero sus detalles iconográficos, inusuales en la representación tradicional del arcángel, como antes comentamos, podrían obedecer, en nuestra opinión, a haberse utilizado el mismo modelo de Cristo resucitado de las cruces de Marcos Hernández, procedente del dibujo de Gaspar Becerra hecho a partir del San Andrés del Juicio Final de Miguel Ángel, sometiendo la figura de la cruz de Puebla a pequeñas modificaciones accidentales para adecuarla y hacerla reconocible bajo esta otra iconografía. Relación con Hernández presenta también el bulto del Crucificado que preside

${ }^{13}$ HEREDIA MORENO, M. Carmen y LÓPEZ-YARTO ELIZALDE, Amelia: $L a$ Edad de Oro de la platería complutense, 1500-1650. Madrid, 2001, pp. 254 y 116.

14 BERLINER, Rudolf: Modelos ornamentales de los siglos XIV-XVIII. Barcelona, s. d., p. 111; GRUBER, Alain: "Grutescos", en Las artes decorativas en Europa (Tomo I). Del Renacimiento al Barroco. Madrid, 2000, p. 178; y HOLLSTEIN, F. W. H.: The new Hollstein Dutch and Fleming etchings engravings and woodcuts 1450-1700. Vol. XLVII. Rotterdam, 1997, pp. 206-214. 
el conjunto. Su tipo físico, de anatomía corpulenta pero de modelado suave, y el tratamiento del paño de pureza lo aproxima al modelo de Valdeavero mejor que al de Bujalaro.

Sin embargo el relieve más interesante por su carácter excepcional es, sin duda y como también antes mencionamos, el de la esfera armilar con la inscripción "MORS MEA VITA VESTRA" y las representaciones del Sol y la Luna, el Ecuador Celeste y la Eclíptica con los signos del zodíaco Escorpión, Libra y Piscis (Figura 6). Es decir, un relieve casi idéntico al de Santorcaz, pero con los signos distribuidos de manera distinta, aunque también aquí en Puebla aparecen intercambiados de manera intencionada respecto a su orden correcto en su revolución aparente desde la Tierra, que sería Libra, Escorpión y Piscis. Todo ello permite suponer que se trata de un horóscopo que, en el marco de una cruz procesional, no puede ser otro que el de la muerte de Cristo, igual que en la de Santorcaz (Figura 7$)^{15}$.

En el caso de Puebla del Vallés, el Ecuador Celeste está orientado de norte a sur, el Sol y la Luna opuestos a ambos lados y con caminos separados. El Sol sobre el Ecuador y la Eclíptica alude a la primavera, y la Luna opuesta, a la Luna llena, es decir a la época de la muerte de Cristo. Piscis es el signo tradicional de Cristo en cuanto a época y a carácter, y se sitúa en el límite del horizonte, porque Jesucristo murió cuando el signo estaba en su ocaso. Libra es el Ascendente y la posición de Júpiter en el nacimiento ${ }^{16}$. Además, el Ecuador y la Eclíptica se cruzan a la altura de Libra, en el equinoccio de otoño, en una alusión a la Segunda Parusía, ya que, según el Libro del Apocalipsis, la Segunda Venida tendrá lugar en un domingo del equinoccio de Otoño, en signo de Libra ${ }^{17}$. El sol sobre el signo de Libra alude al eclipse ocurrido en el momento de la muerte de Cristo según el texto del Apocalipsis: "Cuando el Cordero abrió el sexto sello, se produjo un terremoto violento y el sol se oscureció como un saco de crin y la Luna se volvió toda como de sangre" ${ }^{18}$. Libra se interpreta también como signo de Justicia,

${ }^{15}$ Recuérdese el horóscopo de Cristo de la tabla de la Sagrada Familia (Hispanic Society, Nueva York) que Luis de Morales pintó en el 1563 para el obispo de Badajoz Juan de Ribera o el del arco de ingreso de Santa María de Viana (Navarra) que labró Juan de Ochoa Arranotegui hacia 1555 para el obispo de Calahorra Juan Bernal Díaz de Luco. Ambos fueron analizados por ESTEBAN LORENTE, Juan Francisco: "La naturaleza humana de Cristo, por Luis de Morales", en Don Antonio Durán Gudiol. Homenaje. Huesca, 1995, pp. 253-266; y ESTEBAN LORENTE, Juan Francisco: "El arco de ingreso de la colegiata de Santa María de Viana. Horóscopos de Cristo”, Berceo, 130, 1996, pp. 19-41.

${ }^{16}$ ESTEBAN LORENTE, J. F.: "Horóscopos artísticos de Cristo...", op. cit., p. 139.

17 ESTEBAN LORENTE, Juan Francisco: "1186, Horóscopo del triunfo de Yavé (Apocalipsis XIX)", en IX Congreso Ibérico de Astrología. Poio, 1992, p. 49.

18 Apocalipsis 6, 12. ESTEBAN LORENTE, J. F.: "1186, Horóscopo del triunfo de Yave...”, op. cit., pp. 47-49, aunque en este caso la luna habría que colocarla a la derecha del Crucificado y el sol a su izquierda. 
referido al Juicio Final, y a Cristo como Sol de Justicia, según San Mateo ${ }^{19}$. Por otra parte, Escorpión, el Bajo Cielo según Esteban Lorente, podría aludir a la bajada de Cristo al Limbo. Por último, la inscripción de la esfera "MORS MEA VITA VESTRA" resume este programa astrológico y lo subraya como el horóscopo de la muerte de Cristo. El punto de partida de esta curiosa iconografía pudo ser también, igual que en Santorcaz, la carta astral de Jesucristo que Jerónimo Cardan publicó en Basilea en el año 1554, pocos años antes de la ejecución de estos relieves ${ }^{20}$.

Carecemos de datos documentales precisos, pero, según sus rasgos estilísticos, la cruz de Puebla de Valles hubo de labrarse entre 1565-1575 aproximadamente y suponemos que fue costeada con los fondos de la propia parroquia. Por lo tanto, de acuerdo con la normativa de las Constituciones Sinodales del cardenal Quiroga que se publicaron en el año 1582, pero que, de hecho, estaban en vigor desde años antes, la obra tuvo que contratarse con licencia del visitador y con el visto bueno del Consejo de Gobierno del Arzobispado de Toledo, archidiócesis a la que pertenecía la localidad alcarreña en el siglo XVI ${ }^{21}$.

Por lo tanto, dado que el arzobispo don Bartolomé de Miranda y Carranza estaba procesado por la Inquisición y ausente de Toledo desde 1559, y dadas las relaciones formales y de contenido de la cruz de Puebla con la de Santorcaz que hemos ido poniendo de manifiesto a lo largo de estas páginas, hemos de deducir que el mentor de este programa iconográfico sería el gobernador don Gómez Téllez Girón fallecido en el año 1569 o mejor su sucesor en el cargo, Sancho Busto de Villegas, miembro de la Suprema Inquisición y gobernador de Toledo "en lo espiritual y en lo material" en ausencia de Carranza, entre agosto de 1569 y abril de 1576. Su amplia cultura, en iconografía sagrada y sus profundos conocimientos teológicos le permitirían afrontar con éxito la elaboración del horóscopo de Cristo dentro de los estrictos límites de la ortodoxia católica' ${ }^{22}$, en unos años, recién concluido el Concilio de Trento, en que este tipo de temas resultaba particularmente delicado ${ }^{23}$. A este respecto conviene recordar que de acuerdo con

19 Ibidem, p. 48.

${ }^{20}$ El mismo CARDANO, Girolamo: Mis libros. Madrid, 2002, p. 74, afirma que editó por entonces el De Astrorum iudiciis en diez libros y que en el séptimo se habla de los horóscopos y en el décimo se recogen ejemplos de 200 horóscopos. En la p. 216 añade que la finalidad de la astrología "es en sí misma hermosa: comprender el vínculo que une estas cosas de aquí abajo con las de arriba”. El 6 de octubre de 1570 fue arrestado por la Inquisición. Sobre el pensamiento astrológico de Cardano puede consultarse GRAFTON, Anthony: Cardano's Cosmos: The Worlds and Works of a Renaissance Astrologer. Harvard, 1999.

${ }_{21}$ Constituciones Sinodales del Arzobispado de Toledo, 1582.

${ }^{22}$ Una vez más, hay que subrayar las coincidencias con el caso de Santorcaz, según expusimos en HEREDIA MORENO, M. C. y LÓPEZ-YARTO ELIZALDE, A.: "La cruz de Santorcaz (Madrid)...”, op. cit., p. 271.

${ }^{23}$ Recordemos que el propio Cardan fue procesado por la Inquisición por esta causa. 
las disposiciones conciliares se publicaron sendos índices de libros prohibidos en 1570 y 1583 y que se expurgaron muchos textos astrológicos, incluidos algunos párrafos del propio Cardan ${ }^{24}$.

En cuanto a las fuentes formales de inspiración para este relieve, los artífices pudieron recurrir a estampas alemanas o a libros de astrología, como la versión de Pedro Ciruelo del Opusculum de Spera Mundi o Tratado de la Esfera de Juan de Sacrobosco, impresa en Alcalá de Henares por Miguel de Eguía en el año $1526^{25}$.

Pero el horóscopo de la cruz de Puebla se inserta y adquiere pleno significado en el conjunto de un programa iconográfico más complejo, relativo a la Redención, que incluye los relieves figurativos del árbol y de la manzana. En el anverso del árbol, el pelícano alimentando a sus polluelos, símbolo tradicional del amor filial, se convierte aquí en el supremo acto de Caridad y Amor de Cristo que nos alimenta en la Eucaristía y que dio la vida por todos los hombres -ejemplificados en la figura de San Juan recibido por hijo de María en el monte Calvario ${ }^{26}$, y que garantizó la salvación de los pecadores arrepentidos, como la Magdalena penitente postrada a sus pies. Así lo manifestaron los evangelistas y así lo difundieron los apóstoles que se distribuyen por el reverso del árbol y por la manzana de la cruz. La imagen victoriosa de San Miguel venciendo al demonio según nos narra el Libro del Apocalipsis ${ }^{27}$, prefigura y anticipa en el Antiguo Testamento la del Redentor resucitado, vencedor de la muerte y del pecado. Quizás para subrayar este papel de precursor, el artífice utilizó de manera consciente el modelo del Resucitado de la cruz de Valdeavero para la figura del Arcángel ${ }^{28}$.

En suma, la cruz de Puebla de Valles desarrolla un programa iconográfico que proclama el triunfo de Cristo sobre el pecado a través de su muerte, pero que alude también a su resurrección como garantía de salvación para el género humano. Salvación a la que se puede acceder a través del arrepentimiento y del sacramento de la Penitencia, de acuerdo con el ejemplo de María Magdalena penitente y de acuerdo con las directrices del Concilio de Trento. El programa se completa con la alusión a la Segunda Venida y al Juicio Final a través del signo

${ }^{24}$ HEREDIA MORENO, M. C. y LÓPEZ-YARTO ELIZALDE, A.: "La cruz de Santorcaz (Madrid)...”, op. cit., p. 272.

${ }^{25}$ MARTÍN ABAD, Jesús: La imprenta en Alcalá de Henares, 1502-1600, Madrid, 1991, p. 81. SANTOS QUER, M. A.: "Opusculum de Sphera Mundi: importancia y análisis de sus imágenes en distintas ediciones", en IV Encuentro de Historiadores del Valle del Henares, 1994, p. 675 y ss. analiza las distintas ediciones de la obra.

${ }^{26}$ Para CIRLOT, Juan Eduardo: Diccionario de Símbolos. Barcelona, 1969, p. 368, el pelícano es una de las más conocidas alegorías de Cristo.

${ }^{27}$ En sentido estricto, el Apocalipsis, 12, 7-9 describe a San Miguel venciendo al dragón.

${ }^{28}$ Según REAU, Louis: Iconografía del arte cristiano. T. 1, vol. 1, Barcelona, 1996, p. 71, el culto a San Miguel adquirió renovado impulso y nuevo carácter a partir de la Contrarreforma y su victoria contra Lucifer pasa a simbolizar para los jesuitas el triunfo de la Iglesia Católica contra la herejía protestante. 
de Libra, donde San Miguel, predecesor de Cristo, adquirirá particular relevancia. Por su protagonismo en el Juicio y por su carácter de titular de la parroquia se le otorga un lugar preferente y se le representa de mayor tamaño, como una llamada de atención a los fieles para que se pongan bajo su protección. Es decir, de una forma velada se alude también a la importancia y a la necesidad del culto a los santos, de manera especial a los santos titulares o patronos, según había defendido la Doctrina de Trento ${ }^{29}$. No olvidemos que algunos religiosos y teólogos asistentes al concilio procedían de la Universidad de Alcalá de Henares ${ }^{30}$ y que los decretos conciliares se publicaron en esta localidad inmediatamente después de concluirse el cónclave ${ }^{31}$.

No es extraño que las obras de plata labradas en talleres complutenses por estos años se ajustasen, en la medida de lo posible, a las directrices de la Iglesia de Toledo emanadas de Trento ${ }^{32}$. En este contexto contrarreformista se sitúa la cruz de Puebla de Valles, una obra de segura filiación toledana-complutense según se desprende de su traza, su decoración y sus marcas. La traza general de su árbol cabe adjudicarla a la labor de Marcos Hernández, excepto la solución de los medallones circulares y sus relieves figurativos, que consideramos obra de Gaspar de Guzmán por su semejanza con los equivalentes de la cruz de Bujalaro. Este segundo artífice debió encargarse también de la factura del nudo, mientras que todas o algunas de las figuras de los apóstoles parecen de la mano de Hernández, igual que las imágenes de San Miguel y del Crucificado. Aparte de las estrechas

${ }^{29}$ LÓPEZ DE AYALA, Ignacio: El Sacrosanto y Ecuménico Concilio de Trento. Madrid, 1817. Al culto a los santos y a las reliquias se dedicó la sesión número XXV durante los días 3 y 4 de diciembre de 1563. RODRÍGUEZ, Pedro: El Catecismo Romano ante Felipe II y la Inquisición española. Los problemas de introducción en España del Catecismo del Concilio de Trento. Madrid, 1998.

${ }^{30}$ ALONSO MARAÑÓN, Pedro Manuel, CASADO ARBONÍES, Manuel y CASADO ARBONÍES, Francisco Javier: El Concilio de Trento y los colegios de las "naciones" de la Universidad de Alcalá de Henares: El colegio menor "de León” (1586-1843). Madrid, 2004, p. 55. De la Universidad de Alcalá procedían el jesuita Diego Laínez, Francisco de Torres, profesor de la Sapienza de Roma, Melchor Cano, profesor de la Universidad de Salamanca, Antonio de Solís, maestro de Alcalá, el arzobispo de Granada Pedro Guerrero, portavoz de los conciliares hispanos, el rector del colegio de San Ildefonso Andrés Cuesta o Fernando de Velloso y Francisco de Trujillo, obispos de Lugo y de León respectivamente.

${ }^{31}$ Canones et Decreta Sacrosancti oecumenici [et] generalis Concilii Tridentini, sub Paulo III, Julio III, Pio IIII Pont. Max., Compluti apud Franciscum Cormellas et Petrum Robles M.D.LXIIII. Impresso con licencia... a costa de Alonso Gómez y Juan de Escobedo, libreros en Corte.

${ }^{32}$ El Sínodo Metropolitano de Toledo de 1565 aceptó el Concilio de Trento y el Diocesano de 1566, presidido por el gobernador del Arzobispado Tello Girón acomodó el nuevo orden de Trento al derecho particular de la archidiócesis de Toledo, como recoge GUTIÉRREZ GARCÍA-BRAZALES, M.: Artistas y artífices barrocos..., op. cit. p. 28. 
relaciones que hemos ido señalando a lo largo del texto con otras obras semejantes de ambos artífices, la autoría está confirmada por las marcas que ostenta la pieza (Figura 2).

La marca de localidad reproduce el formato de la primera variante conocida de la entonces villa del Henares, que estuvo en vigor entre 1500 y 1600: castillo con tres torres escalonadas sobre el nombre de la villa desarrollado en dos líneas en caracteres goticistas - castillo/ALC/ALA-, igual que la que ostentan las cruces de Pioz, Bujalaro o Santorcaz, entre otras muchas piezas ${ }^{33}$. En cuanto a las nominales, una de ellas, de formato cuadrangular, desarrolla en dos líneas el nombre de MAR/COS, con la misma impronta de las señales conocidas del artífice Marcos Hernández. La segunda, reproduce en dos líneas la inicial del nombre y el apellido completo de Gaspar de Guzmán -G./GVZMAN-según el punzón utilizado habitualmente por el platero complutense, es decir, en letras capitales, con la $\mathrm{Z}$ dentro de la $\mathrm{V}$ y la A unida al palo vertical de la $\mathrm{M}$.

De acuerdo con el sistema de triple marcaje que se estaba implantando en Alcalá de Henares en la década de 1570, una de las marcas nominativas debía de corresponder al artífice de la obra y la segunda al marcador de la misma. Pero, según el actual estado de la cuestión, ninguno de estos dos plateros ejerció este oficio municipal en ningún momento de su trayectoria profesional. Además, los marcadores complutenses solo utilizaron su marca personal durante los años setenta de forma esporádica, como lo hicieron Téllez y Castillo, por ejemplo. Pero su uso sistemático no se impondría en Alcalá de Henares hasta los años ochenta del Quinientos. Además, la pérdida de las actas municipales de las décadas de 1560 y 1570 impide conocer al detalle quiénes fueron los individuos elegidos para ocupar el puesto y cuáles fueron sus límites cronológicos concretos durante esta década ${ }^{34}$.

Por lo tanto, de acuerdo con el actual estado de la investigación, se puede asegurar que la cruz de Puebla de Valles es el resultado de la colaboración entre Marcos Hernández y Gaspar de Guzmán, actuando ambos en calidad de autores, aunque precisar su cronología exacta resulta complicado porque tampoco se conservan los libros de fábricas de la parroquia. De hecho, el análisis detenido de la cruz nos ha ido confirmando la relación técnica y estilística de determinados elementos con uno u otro maestro. No existen precedentes en la platería de Alcalá de dos plateros que marquen una misma obra como autores de la misma. Pero sí hay algún caso de colaboración o de participación de dos artífices distintos en la misma pieza. Recordemos, por ejemplo, que la cruz que hoy se guarda en la Fundación Selgas Fagalde de Asturias, procedente, quizás, de Pezuela de las Torres (Madrid), fue contratada por Antonio Faraz, pero la terminó de labrar su

${ }^{33}$ HEREDIA MORENO, C. y LÓPEZ-YARTO ELIZALDE, A.: La Edad de Oro..., op. cit., p. 59.

${ }^{34}$ Ibidem, pp. 62-63. 
hermano Juan Francisco ${ }^{35}$. El propio Gaspar de Guzmán parece que colaboró con Antonio Faraz, su probable maestro, en la cruz de Pioz, a juzgar por algunos pagos de esta obra que se hicieron a su nombre.

La falta de documentos impide precisar la cronología exacta y las circunstancias concretas del encargo de la cruz de Puebla de Valles, pero podemos aventurar algunas hipótesis. Teniendo en cuenta que, de acuerdo con los datos que conocemos, Gaspar de Guzmán no viajó nunca a Toledo, es evidente que sus contactos y su relación profesional con Marcos Hernández tuvieron que producirse en Alcalá de Henares o en su entorno. Hernández sí se desplazó a tierras complutenses en varias ocasiones, según consta por documentos diversos. Según estas fuentes documentales, su primer viaje tendría lugar posiblemente con motivo de la entrega de la cruz de la parroquia de Valdeavero, localidad del alfoz complutense limítrofe con la provincia de Guadalajara.

La cruz se había contratado en Toledo en 1566, pero los pagos se prolongaron hasta el 1575. Entre ambas fechas el artífice debió residir en la villa universitaria, durante un tiempo indeterminado pero lo suficientemente amplio para que figurase como vecino de Alcalá cuando el cabildo de Toledo lo reclamó en el año 1574 con el objeto de que participara en la tasación de los facistoles de la catedral primada hechos por Nicolás de Vergara el Mozo ${ }^{36}$. Entre 1570-1571 y 1574, aprovechando su estancia en Alcalá, es probable que Marcos recibiese algún otro encargo. Con su estilo y con el de Guzmán se relacionan, por ejemplo, la arqueta de plata que hoy guarda las reliquias de los Santos Niños en la Magistral de Alcalá y que se custodia, a su vez, en el interior de la que los hermanos Zurreño confeccionaron a comienzos del siglo XVIII, o la de la parroquia complutense de Santa María que se conserva actualmente en el arzobispado de Madrid $^{37}$. Es decir, suponemos que los primeros contactos entre Hernández y Guzmán se produjeron a comienzos de los años setenta del siglo XVI y que dieron lugar al cambio de estilo de este último, como se advierte en la cruz de Santorcaz concluida antes de 1577 y en las custodias de la catedral de Sigüenza y El Casar de Talamanca (Guadalajara) labradas por las mismas fechas ${ }^{38}$. Todas estas obras muestran la cabal asimilación del lenguaje formal y estético del toledano por parte de Guzmán.

${ }^{35}$ Ibidem, pp. 241-243, analizan la compleja problemática de esta pieza.

${ }^{36}$ Datos dados a conocer por PÉREZ SEDANO, F.: Datos documentales inéditos para la historia del arte español. I. Notas del archivo de la catedral de Toledo. Madrid, 1914, recogidos en nuestro trabajo HEREDIA MORENO, M. C. y LÓPEZ-YARTO ELIZALDE, A.: "Una aproximación a la obra del platero Marcos Hernández...", op. cit., pp. 317-318.

${ }^{37}$ HEREDIA MORENO, M. Carmen: "Arquetas nobiliarias de la segunda mitad del siglo XVI para el servicio de la Iglesia”, Archivo Español de Arte, 331, 2010, pp. 267-286.

${ }^{38}$ LÓPEZ-YARTO ELIZALDE, Amelia y HEREDIA MORENO, M. Carmen: "Precisiones sobre la custodia de la catedral de Sigüenza", Archivo Español de Arte, 292, 2000, pp. 303-313. 
Teniendo en cuenta estas circunstancias, es muy probable que el comitente de la cruz de Puebla de Valles hubiese tenido ocasión de conocer la de Valdeavero y, quizás también, la de Santorcaz entonces en curso de realización, y quisiera conjugar en esta nueva obra las novedades formales e iconográficas de las dos cruces anteriores. También es posible que el contrato se firmase únicamente con Hernández, un artífice de fama cuya actividad debía ser ya bien conocida y estimada en Alcalá por sus frecuentes estancias en la villa universitaria, pero su marcha a Toledo en el año 1574 propiciaría la continuación y terminación de la cruz a manos de Gaspar, el platero complutense que mejor había asimilado su estética ${ }^{39}$.

Como tercera opción, apuntamos la posibilidad de que la cruz de Puebla se contratase con Gaspar de Guzmán a comienzos de los años ochenta y que, tras su muerte (c. 1585) sin haber podido concluirla, el comitente se viera obligado a hacer un segundo contrato. La elección de Marcos Hernández para la terminación de esta empresa estaría justificada por su conexión estilística con el maestro fallecido, por su prestigio y por la continua actividad que estaba desarrollando por tierras complutenses y por la provincia de Guadalajara por estos años ${ }^{40}$. Entre 1583 y 1594 se documentan varias restauraciones llevadas a cabo por Hernández para la parroquial de Meco, así como las hechuras de la cruz de la parroquia de Camarma de Esteruelas y de un cáliz para Alovera (Guadalajara), entre algunos otros trabajos ${ }^{41}$.

${ }^{39}$ La relación de Guzmán con el norte de la provincia de Guadalajara durante estos años se extiende por otras localidades. Según un documento inédito del Archivo de la Real Chancillería de Valladolid (A.R.C.V.), Registro de Ejecutorias, caja 1345, 40, fechado en 12 de marzo de 1577, Juan, Esteban, Francisco y Alonso Bueno, vecinos de Torija (Guadalajara), como cesionarios del conde de Coruña don Lorenzo Suárez de Mendoza, pusieron pleito a Gaspar de Guzmán, Cristóbal de Villalta y Alonso Guillén, plateros de Alcalá de Henares, sobre la devolución de doce platos de plata que el repostero del Conde, Juan de Losada, había vendido.

${ }^{40}$ Sin embargo, Hernández mantuvo sus contactos con Toledo durante estos años. Otro documento inédito del A.R.C.V., Registro de Ejecutorias, caja 1686, 1, fechado en 2 de noviembre de 1591 nos informa sobre un pleito litigado por Marcos Hernández, vecino de Toledo, por cuantía de 33.412 maravedíes que debía a su colega toledano Miguel Gallego en virtud de un censo impuesto en el año 1571 sobre unas casas en la parroquia de San Tiuste. Hernández reconoce deber a Gallegos esta cantidad que mandó se la pagase la iglesia de Santa Catalina de Puente del Arzobispo con el importe de la cruz que había hecho para la iglesia y que todavía le estaban debiendo. CEÁN BERMÚDEZ, Juan Agustín: Diccionario histórico de los más ilustres profesores de las Bellas Artes en España. T. II. Madrid, 2001, p. 271, nos informa que en 1594 Marcos volvió a ser llamado a Toledo para tasar el arca de reliquias de Santa Leocadia que había hecho Francisco Merino según dibujos de Nicolás de Vergara el Mozo.

${ }^{41}$ HEREDIA MORENO, M. C. y LÓPEZ-YARTO ELIZALDE, A.: La Edad de Oro..., op. cit., p. 324. 
En todo caso, la calidad de la cruz de Puebla de Valles es palpable y su origen y su autoría se confirman por sus marcas y por su estilo. Además, su iconografía resulta original en el panorama de platería española contemporánea, solo equiparable esta última a la de la cruz de Santorcaz labrada en parecidas fechas. En suma, la cruz de Puebla es una pieza digna de la categoría de sus autores, Marcos Hernández y Gaspar de Guzmán, y del centro platero de Alcalá de Henares que en estos momentos se encontraba en pleno apogeo de su Edad de Oro y en el cénit de su producción artística.

Fecha de recepción: 19 de enero de 2017

Fecha de aceptación: 24 de enero de 2017

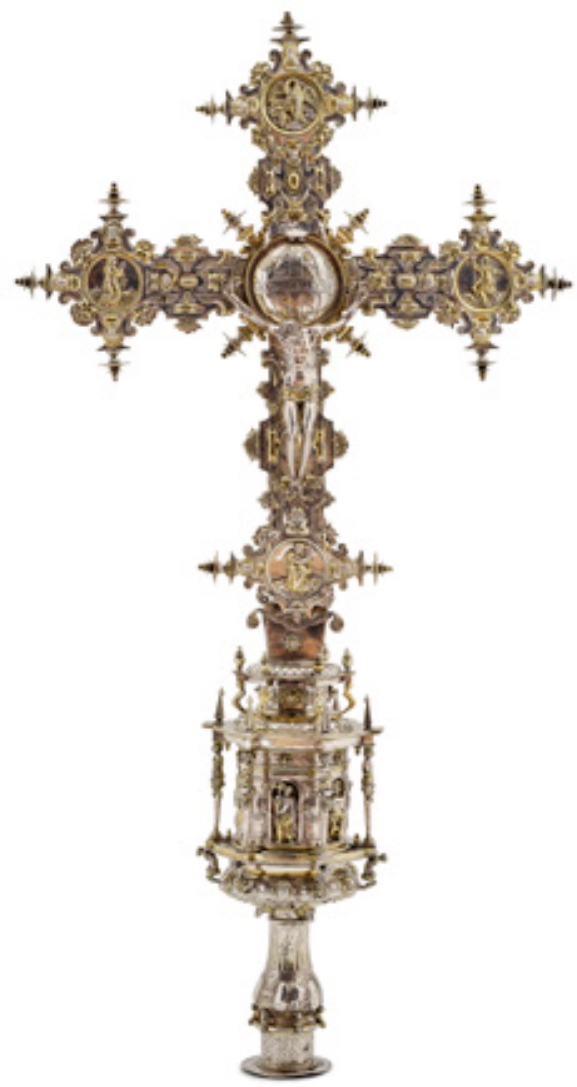

Figura 1. Gaspar de Guzmán y Marcos Hernández, cruz procesional, c. 1570-1575, Puebla de Valles. Foto facilitada por José Domingo Delgado Bedmar. 


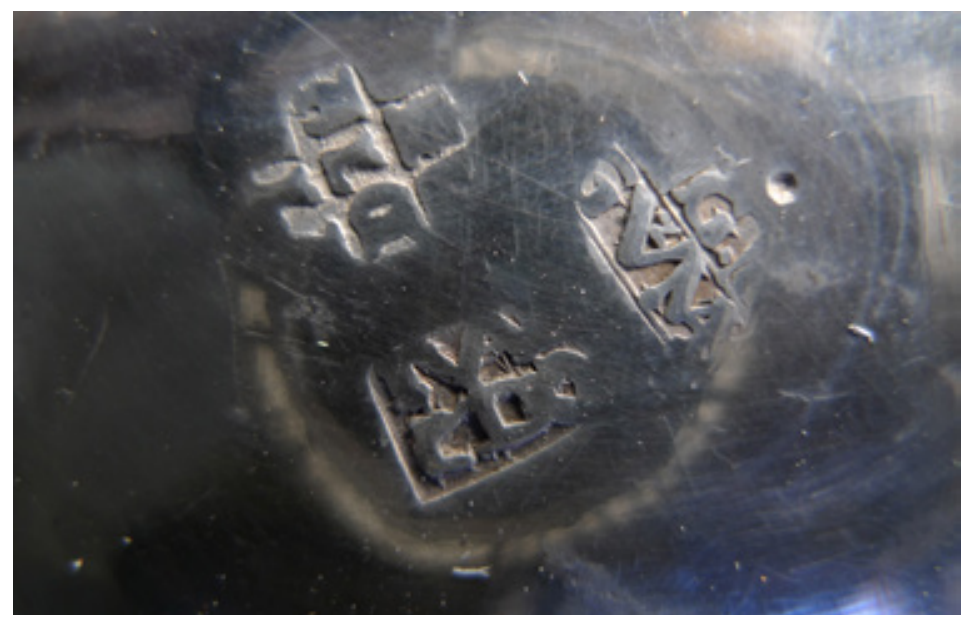

Fig. 2. Marcas, cruz procesional, Puebla de Valles. Foto procedente del Informe Técnico de $\mathrm{M}^{\mathrm{a}}$ Dolores Ortín Arranz, Instituto de Restauración y Conservación de la Comunidad de Castilla-La Mancha.

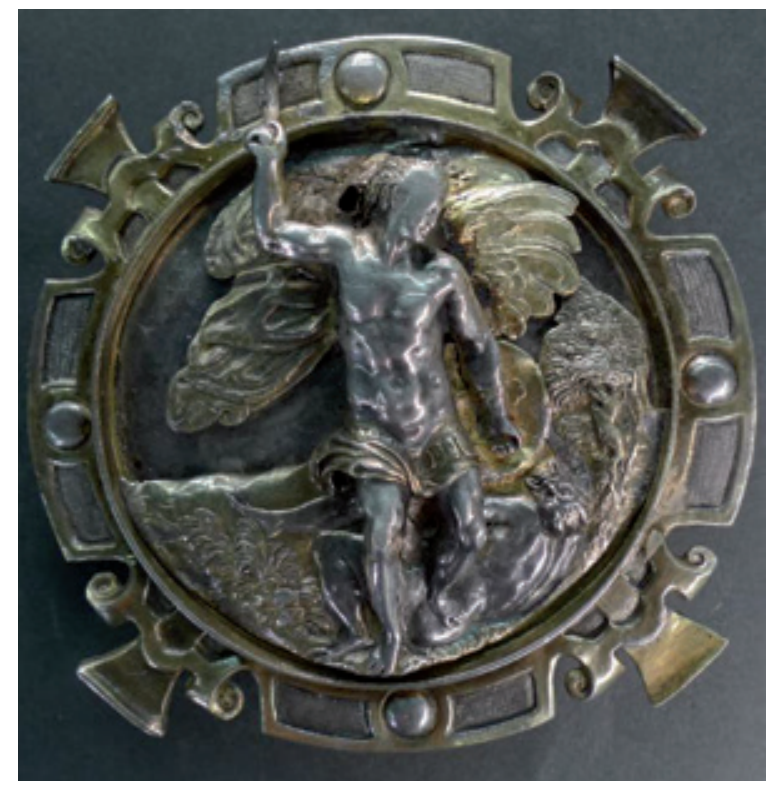

Figura 3. San Miguel, cruz procesional, Puebla de Valles. Foto procedente del informe técnico de $\mathrm{M}^{\mathrm{a}}$ Dolores Ortín Arranz, Instituto de Restauración y Conservación de la Comunidad de Castilla-La Mancha. 


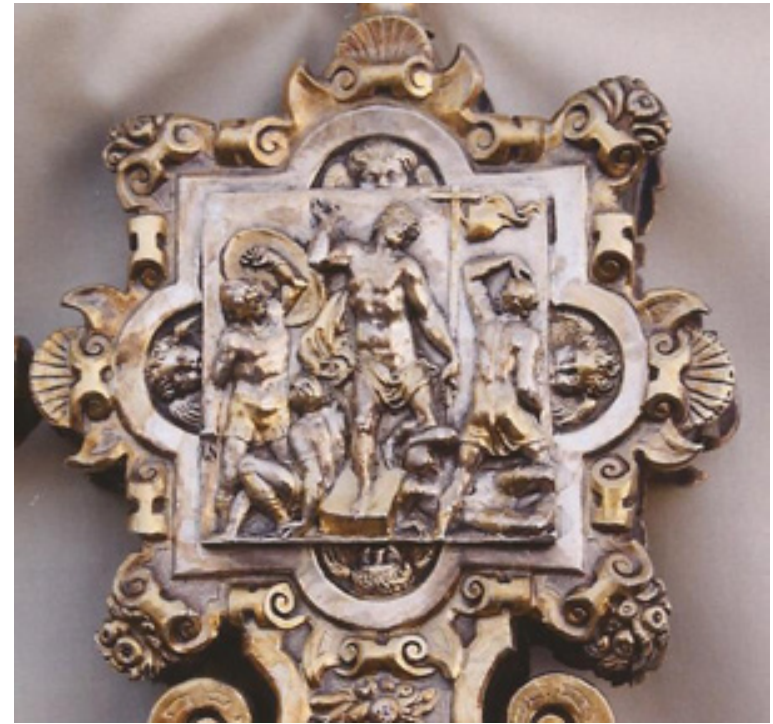

Figura 4. Marcos Hernández, San Miguel, cruz procesional, c. 1570, Valdeavero.

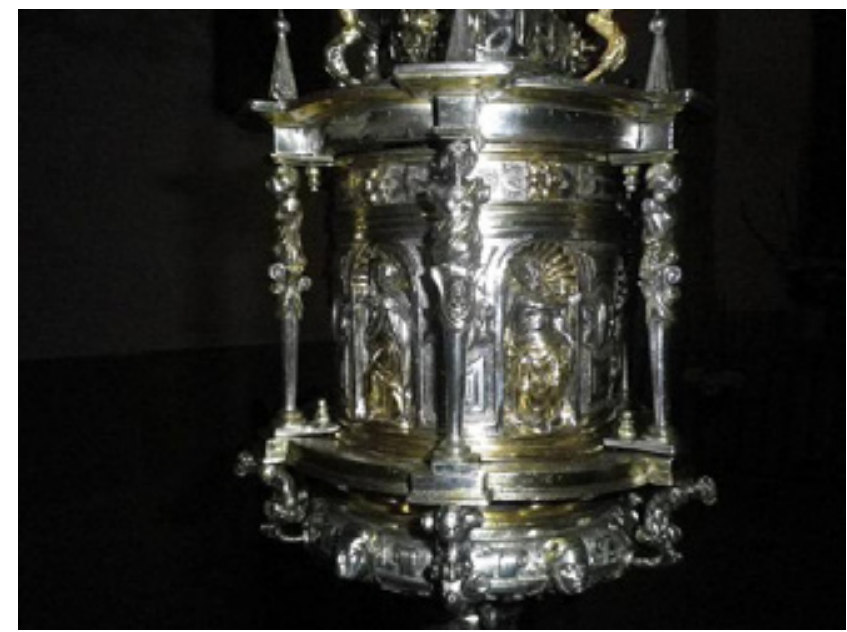

Figura 5. Manzana (detalle de la fig. 1), cruz procesional, Puebla de Valles. 


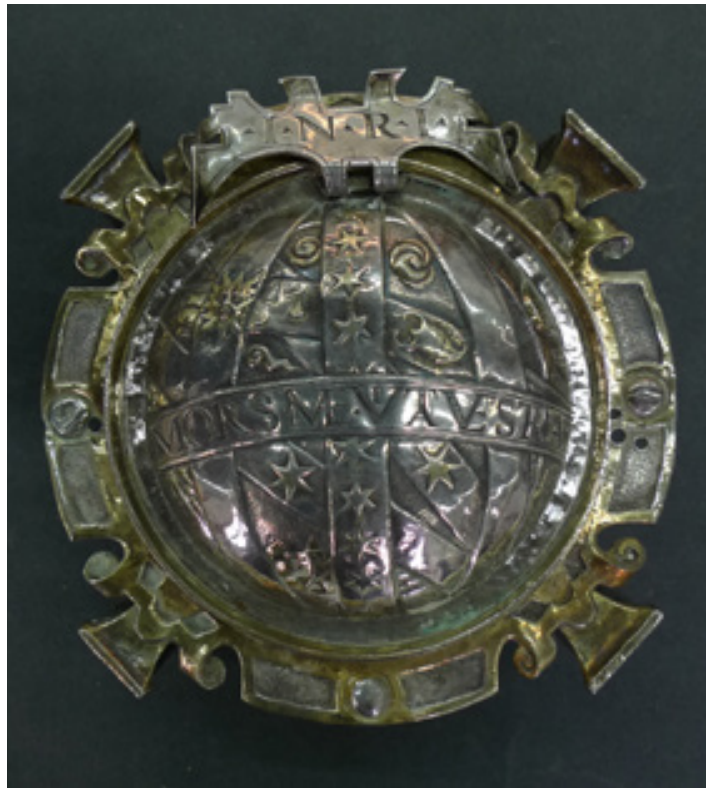

Figura 6. Esfera armilar, cruz procesional, Puebla de Valles. Foto procedente del informe técnico de $\mathbf{M}^{\mathrm{a}}$ Dolores Ortín Arranz, Instituto de Restauración y Conservación de la Comunidad de Castilla-La Mancha.

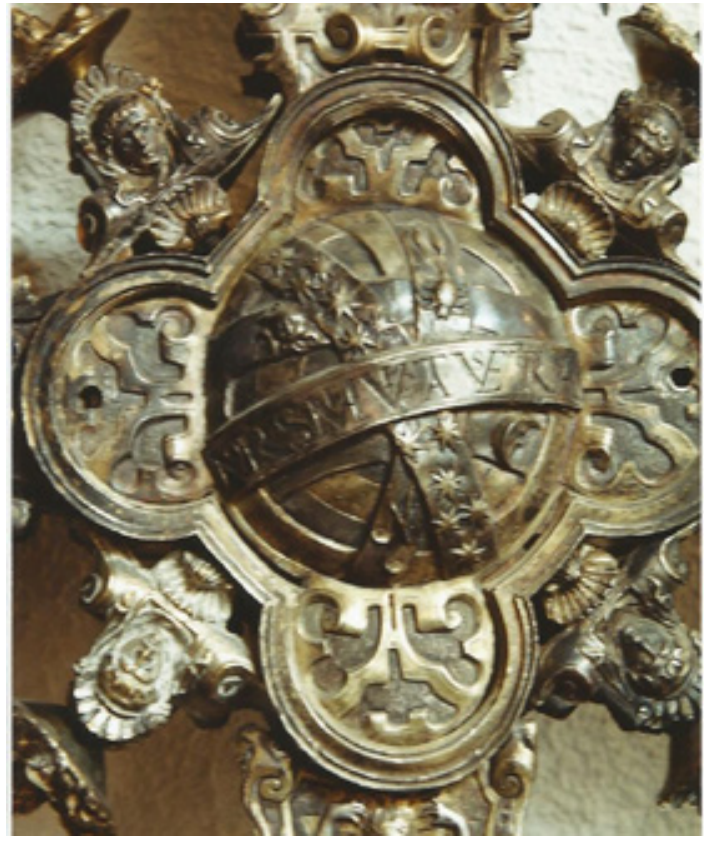

Figura 7. Gaspar de Guzmán, esfera armilar, cruz procesional, 1577, antorcaz.

LABORATORIO DE ARTE 29 (2017), pp. 177-192, ISSN 1130-5762 e-ISSN 2253-8305 - DOI http://dx.doi.org/10.12795/LA.2017.i29.08 